\title{
EDITORIAL
}

\section{Nuestra responsabilidad en la reforma a la salud}

$\mathrm{L}$ a Ley 1751 del 16 de febrero de 2015 o Ley Estatutaria de la Salud es una de las mayores conquistas en favor de los ciudadanos que ha logrado el gremio médico en el mundo y esa conquista ocurrió en Colombia. Su objeto es garantizar el derecho fundamental a la salud, regularlo y establecer sus mecanismos de protección, es un derecho autónomo e irrenunciable en lo individual y en lo colectivo.

La Gran Junta Médica Nacional, constituida por todas las agremiaciones médicas del país y liderada por la Academia Nacional de Medicina, logró presentar un articulado concreto que, así como los mandamientos de la ley de Dios se resumen en "amar a Dios sobre todas las cosas y al prójimo como a sí mismo", aquí se resumen los 24 artículos que la contienen en que "el Estado reconoce el derecho a la salud de cada uno de los colombianos como un derecho fundamental", eso significa que el Estado debe adoptar las políticas necesarias para asegurar la igualdad de trato y oportunidades en el acceso a la atención, la promoción de la salud, como también la prevención, el diagnóstico, el tratamiento, la rehabilitación y la paliación de la enfermedad para todos los colombianos. Se debe garantizar la autonomía de los profesionales de la salud para ejercer su profesión, dentro de un marco de autorregulación, ética, racionalidad y evidencia científica. Es decir, hay unos derechos y también unos deberes. Así mismo, el talento humano en salud estará amparado por condiciones laborales justas y dignas, con estabilidad y facilidades para incrementar sus conocimientos.

Ha sido tan larga la transición desde cuando se emitió la ley, por cuanto de manera oficial no se ha derogado radicalmente la Ley 100 de 1993, que convirtió a la salud en un fortín para el desfalco y hurto de los dineros públicos, y todos aquellos que usufructuaron de la intermediación financiera de la salud no quieren perder esta oportunidad que les brindó el mismo Estado colombiano.

Nos corresponde a cada una de las sociedades científicas, entre ellas a la Asociación Colombiana de Endocrinología, Diabetes y Metabolismo, contribuir a que la ley estatutaria de la salud sea un camino expedito, en beneficio de la salud mental y física de cada uno de los colombianos. En la medida en que se regule la ley, a partir del riguroso cumplimiento de cada uno de sus artículos, y que nuestro ejercicio profesional sea intachable, donde se destaque el profesionalismo (la ética, la empatía, el humanismo), el derecho fundamental a la salud será una realidad.

Para la implementación de la ley, el Ministerio de Salud ha emitido una serie de resoluciones que en el fondo tratan de controlar el sistema. Aquí radica un mal mayor porque así como nuestro organismo para poder funcionar de manera eficiente, eficaz y con efectividad requiere que cada uno de sus órganos esté interrelacionado con todos los demás, en Colombia no funciona la salud, porque la corrupción galopante se propicia por cuanto no se cumplen los requisitos que debe tener un "sistema".

Hay una desarticulación total en la información:

No hay una historia clínica única y sistematizada. Esto ha impedido que el Ministerio de Salud esté al tanto de lo que verdaderamente ocurre en las IPS y en las EPS.

No hay una base única de salud de los afiliados, esto ha permitido que en las IPS se inventen pacientes, diagnósticos, tratamientos, etc. (cartel de la hemofilia, del sida), y se manipulen historias clínicas. En las EPS explotan a su favor la unidad de pago por capitación, haciendo reportes de pacientes ya fallecidos y haciendo recobro de servicios que no están en el plan de beneficios o inversión de recursos públicos con fines distintos a los que requieren los pacientes. Por eso, desde la Asociación Colombiana de Sociedades Científicas vemos con beneplácito el Mipres, instrumento para obtener información fehaciente de lo que se ordena y que se ha ido enriqueciendo con la información que se obtiene de las mismas sociedades científicas. No hay que mirar esta herramienta como una afrenta a la autonomía médica, por el contrario, nos permite ejercer autorregulación; sin embargo, su implementación requiere un mayor tiempo dedicado a la consulta y a la atención del paciente, y esto desafortunadamente no se ha tenido en cuenta. 
No hay un sistema de información unificada de insumos de laboratorios y de dispositivos médicos, lo cual ha permitido cobros injustificados por servicios no prestados o dispositivos no colocados o sobrefacturados. ¿Qué responsabilidad nos cabe a los profesionales de salud?, proceder con ética y con profesionalismo, hacer bien nuestro trabajo, como decía nuestro Nobel de Literatura: "el deber revolucionario de un escritor es escribir bien", se podría de forma análoga decir que "el deber revolucionario de un médico es atender con profesionalismo y con humanismo a su paciente".

Desde la Academia Nacional de Medicina y el Ministerio de Salud y Protección Social se instaurarán diez mesas de trabajo con el objetivo de implementar la ley estatutaria. Allí estaremos representados como Asociación Colombiana de Sociedades Científicas y nos enfocaremos en la autonomía y autorregulación, la sostenibilidad financiera del sistema, el estatuto del personal de salud, y en los indicadores de seguimiento al goce efectivo del derecho fundamental a la salud.

No nos cabe duda de que hace falta con urgencia una reforma a la salud, como también que ésta está contenida en la ley estatutaria.

Desde la Gran Junta Médica Nacional se viene trabajando en hacer cumplir la ley, para que se termine de una vez por todas con la intermediación financiera que creó la Ley 100 de 1993. Para que el Estado sea el único rector, director y coordinador de la política de salud pública, con el acompañamiento de la sociedad civil, de las universidades, de las sociedades científicas, etc.; para que la red pública sea fortalecida y, en especial, los hospitales universitarios; para promover una clara y decidida política pública de desarrollo y fortalecimiento del talento humano en salud que incluya un cambio estructural en la formación, priorizando el desarrollo intelectual, ético y cultural como fundamento de la educación profesional. Así mismo, que los residentes de las especialidades médicas, que aportan trabajo asistencial y docente, indispensable en los hospitales, reciban un estipendio como médicos que son, por su trabajo asistencial y que, de alguna manera, el pago de sus matrículas sea cubierto desde un fondo especial destinado para ello. Que se garantice el reconocimiento de la dignidad y estabilidad de los trabajadores de la salud, con condiciones laborales justas y socialmente equitativas, lo cual se logrará integralmente con las organizaciones gremialmente fortalecidas.

No sobra insistir en que la reforma no será una realidad mientras no se implemente un sistema de información integral electrónica en las entidades de salud con disponibilidad y acceso de las personas autorizadas y garantizando la confidencialidad de la misma. Igualmente, se deben generar los mecanismos para que los entes de control y vigilancia pública sancionen y suspendan a las entidades públicas y privadas que no cumplan con su función. La Superintendencia Nacional de Salud debe ser un organismo de control independiente del Ministerio de Salud, como son las demás superintendencias, y su papel debe ser protagónico en este sentido.

El llamado a todos y cada uno de los médicos especialistas es a que se asuma una posición más que exigente, participativa, donde se antepongan los intereses del bien común a los intereses particulares, solo así podremos con el ejemplo producir verdaderos cambios.

\section{José Ricardo Navarro Vargas, MD.}

Decano de medicina de la Universidad Nacional de Colombia

Expresidente Sociedad Colombiana de Anestesiología y Reanimación S.C.A.R.E.

Expresidente Asociación Colombiana de Sociedades Científicas 